\title{
Links between adolescent bullying and neural activation to viewing social exclusion
}

\author{
Michael T. Perino ${ }^{1}$ • João F. Guassi Moreira ${ }^{2}$ • Eva H. Telzer ${ }^{3}$ \\ Published online: 10 July 2019 \\ (C) The Psychonomic Society, Inc. 2019
}

\begin{abstract}
Neuroscientists who have studied bullying have primarily focused on the psychopathology of diagnosable offenders or the resulting symptomatology of victimization. Less attention has been given to theories that suggest that bullying may be an interpersonal strategy. In an exploratory study, we recruited a sample of adolescents $(\mathrm{N}=24)$ who engaged in high rates of delinquent behavior and collected self-report ratings of bullying behaviors. During an fMRI scan, adolescents observed instances of social exclusion and social inclusion. The adolescents' self-reported bullying was associated with greater ventral striatum, amygdala, medial prefrontal cortex, and insula activation when viewing social exclusion $>$ social inclusion. Activation in these regions is commonly associated with reward-learning, salience monitoring, and motivational processes, suggesting that bullies show altered processing of interpersonal cues and social dynamic experiences in their environment. Our findings highlight the need for developmental neuroscientists to further explore the role of social motivation in processing socio-affective information, with a particular focus on goal-directed antisocial behavior.
\end{abstract}

Keywords Bullying · Aggression · fMRI · Cyberball

\section{Introduction}

Bullying is widely regarded as a ubiquitous feature of the schooling experience (Berger, 2007; Book, Volk, \& Hosker, 2012; Volk, Camilleri, Dane, \& Marini, 2012). Approximately one in five high school students report being bullied within the last calendar year (Gladden, Vivolo-Kantor, Hamburger, \& Lumpkin, 2014). A smaller proportion of middle- and highschool students report that their experience with bullying is a constant struggle (Robers, Zhang, Truman, \& Snyder, 2010). Given the high interpersonal and financial costs associated with bullying (Phillips, 2012; Baams, Talmage, \& Russell, 2017; Copeland, Wolke, Angold, \& Costello, 2013), it is not surprising there would be a desire to understand why bullying

Eva H. Telzer

ehtelzer@unc.edu

1 Department of Psychiatry, Washington University School of Medicine in St. Louis, St. Louis, MO, USA

2 Department of Psychology, University of California, Los Angeles, Los Angeles, CA, USA

3 Department of Psychology \& Neuroscience, University of North Carolina, Chapel-Hill, 235 E Cameron Avenue, Room 213D, Chapel Hill, NC 27599, USA occurs and how neuroscience may help to optimize interventions (Viding, McCrory, Blakemore, \& Frederickson, 2011). However, much of the neuroscientific research into bullying has focused on victimization and social exclusion (MacDonald \& Jensen-Campbell, 2011; Masten \& Eisenberger, 2009; Sebastian et al., 2011; Vaillancourt, Hymel, \& McDougall, 2011; Vaillancourt, Hymel, \& McDougall, 2013; Vijayakumar, Cheng, \& Pfeifer, 2017), with less explicit focus on those engaging in the bullying behaviors themselves. Furthermore, research into offenders has tended to focus on psychopathology correlated with bullying, such as conduct disorder or psychopathy (Blair, Veroude, \& Buitelaar, 2016), rather than on bullying. Focusing on specific acts and processes (Krakauer, Ghazanfar, Gomez-Marin, Maciver, \& Poeppel, 2017), such as viewing harmful acts within social context, rather than more generally examine conditions correlated with bullying will give researchers, clinicians, and educators greater insight into why bullying occurs. The goal of the current study was to focus specifically on how variations in bullying relate to neural activation differences in adolescents when viewing social exploitation relative to social inclusion.

Bullying is a specific subset of aggressive interpersonal acts, where an aggressor commits intentional (often repetitive) behaviors that exploit or further social power imbalances 
(Volk, Dane, \& Marini, 2014). Bullying can take many forms, such as physical, verbal, psychological, or written threats, and has deleterious effects on those victimized (Center for Disease Control [CDC], 2016; Olweus, 2003). Importantly, a dearth of research has examined bullying using social paradigms, which, in part, may be due to a theoretical reliance on viewing bullying and other aggressive acts as stemming from dysfunction and pathology (Blair et al., 2016), rather than as a dynamic social strategy (Bjorklund \& Hawley, 2014). While research has found evidentiary support for social information processing accounts for adaptive forms of aggression (Dodge, Lochman, Harnish, Bates, \& Pettit, 1997; Stickle, Kirkpatrick, \& Brush, 2009), less of this work has been applied to the neurodevelopmental literature (Hyde, Shaw, \& Hariri, 2013), where there has been significantly more attention paid to theoretical constructs, such as conduct disorder and psychopathy (Blair et al., 2016). Notably, there has been at least one attempt to provide social-game paradigms that may identify bullying behavioral patterns (Mancilla-Caceres, Espelage, \& Amir, 2015), but these have not been widely adapted for fMRI use.

Empirical work examining bullying as an alternative strategy for navigating social environments has provided some interesting work, suggesting the potential utility of bullying (Book et al., 2012; Farrell, Della Cioppa, Volk, \& Book, 2014; Volk et al., 2014; Volk, Farrell, Franklin, Mularczyk, \& Provenzano, 2016). In short, the hypothesis is that while societally undesirable, social aggression can be beneficial at the individual level in some contexts (Bjorklund \& Hawley, 2014). Three main lines of research support such a stance. First, ethologists have long noted that aggressive behaviors akin to bullying, where aggression is utilized for the sake of instrumental gain in status or resources at the expense of others, are pervasive in the animal kingdom (Alcock, 1989; Masure \& Allee, 1934), including species closely related to humans, such as great apes (Goodall, 1986; Pederson, King, \& Landau, 2005). Second, empirical work has tied developmental stressors, such as neglect or trauma, to both aberrant neurodevelopment of affective processing regions and adolescent delinquency (Caldwell et al., 2015), suggesting that very early behavioral indicators of aggression may change developmental trajectories. Perhaps, when exposed to a stressor, some individuals may develop a risky life-strategy (Figueredo \& Jacobs, 2010), predisposing them to later bullying behaviors and aggression (Ellis \& Bjorklund, 2012). Third, a growing number of studies have shown that individuals who engage in higher rates of aggression coincidentally have a number of positive developmental outcomes. For instance, bullying is linked to higher rates of popularity (Rose, Swenson, \& Waller, 2004), greater social status (Hawley, Little, \& Card, 2007; Juvonen, Graham, \& Schuster, 2003), and intact social intelligence (Kaukiainen et al., 1999). Moreover, adolescent peers often nominate bullies as "leaders" in their social environments (Vaillancourt, Hymel, \& McDougall, 2003), a result consistent in adult samples (Maner, 2017). This research suggests that bullying is not specific to humans, may be a behavioral profile triggered as a means of surviving harsh environments, and may situationally confer benefits. Building on these findings, there have been calls to explore antisocial behaviors in ways that also account for these beneficial outcomes (Ellis et al., 2012) and attempt to understand the development and heterogeneity of antisociality within more specific contexts (Dodge \& Albert, 2012).

Given the unique distinction of bullying as aggression for personal benefit (Hawley, 2011), it is important to examine the construct and how it differs from the broader aggression literature (Hawley, Stump, \& Ratliff, 2011). Bullying may provide a potential bridge for researchers to reconcile conflicting findings within the aggression literature. While dysfunction is important to study, past studies of aggression may be oversampling on pathological offenders, which would suggest that past results: a) would not align when sampling "successful offenders," who show little to no neurophysiological dysfunction (Gao \& Raine, 2010; Raine, Yang, Narr, \& Toga, 2011); b) would not be reflective of the individuals engaged in bullying, who have been shown in large samples not to have widespread socioemotional impairments (Kaukiainen et al., 1999; Garandeau \& Lansu, 2019); or c) would not be comparable to aggression that serves some motivational purpose (Rai \& Fiske, 2012), which has been suggested as a cause of adolescent bullying (Hawley, 1999; Juvonen \& Ho, 2008; Sharp, Carolyn, \& Fonagy, 2011).

While bullying can likely be studied as a normative process (Little, Brauner, Jones, Nock, \& Hawley, 2003), particularly given how it has been studied in successful adult populations (Maner, 2017), we focused on delinquent adolescents for whom bullying behaviors tend to be higher (Bender \& Lösel, 2011). In this exploratory study, we utilized functional magnetic resonance imaging (fMRI) to examine the neural correlates of viewing social aggression, particularly in relation to self-reported bullying within the sample. If bullying functions as a behavioral strategy for navigating social environments, adolescents should be particularly attuned to social scenarios where social hierarchy cues are present. For example, one recent study found adolescent bullies knew what was socially desirable, accurately recognized their behavior made them unlikeable, and still continued bullying, because they viewed the social status increments as more important than likeability decrements (Garandeau \& Lansu, 2019). We hypothesize that when viewing socially aggressive behavior, bullying will be related to hyperactivation in regions associated with: a) motivational processing, such as the ventral striatum (Zink, Pagnoni, Martin, Dhamala, \& Berns, 2003) and amygdala (Cunningham \& Brosch, 2012); b) social perception, such as the medial prefrontal cortex and temporoparietal 
junction (Mills, Lalonde, Clasen, Giedd, \& Blakemore, 2014); and c) salience monitoring (Lamm, Decety, \& Singer, 2011), such as the anterior cingulate cortex (Menon \& Uddin, 2010) and ventral tegmental area (Bromberg-Martin, Matsumoto, \& Hikosaka, 2010). Furthermore, we hypothesize that neural activation observed in our task will be specific to adolescents reporting higher bullying, and not delinquency, because delinquency is heterogeneous and the root cause is not inherently linked to motivational factors (Thompson \& Morris, 2016). How bullies neurally process instances of social aggression (i.e., viewing a bully engage in dominant, aggressive behavior toward a targeted individual compared with egalitarian behavior) will provide insight into whether there is evidence for aggression as motivated cognition (Balcetis \& Dunning, 2006), where recruitment of perceptual resources for cues relevant to an individual's goals would be required (Gantman \& Van Bavel, 2015).

\section{Methods and materials}

\section{Participants}

Twenty-four adolescents (12 females; aged 13.1-17.7 years, $\mathrm{M}_{\text {age }}=16.2$ years, $\mathrm{SD}=1.2 ; 50 \%$ black, $50 \%$ white) with a history of behavioral conduct problems were recruited from a town in Midwestern United States to participate in a neuroimaging study. We targeted individuals who had recently engaged in delinquent behaviors that warranted school or legal intervention, including targeted bullying, threatening and intimidation of others, initiating physical fights, using weapons, stealing, and/or drug use. Participants were recruited through a number of community sources, including an alternative school consisting of students who have been multiply suspended or expelled, the local juvenile detention center, and the local probation office. Based on self-reports, 14 participants reported at least one previous expulsion from school, 23 reported at least one suspension from school, and 12 reported being arrested at least once (Table 1). The University's Institutional Review Board approved all study procedures, and participants and caregivers provided written assent and consent, respectively. Adolescents were compensated $\$ 50$ for their participation.

Table 1 Percent of sample engaging in disciplinary acts $(\mathrm{N}=24)$

Number of times disciplinary act occurred

\begin{tabular}{lllllllll} 
& 1 & 2 & 3 & 4 & 5 & 6 & 7 & $8+$ \\
\hline Suspensions & $8.3 \%$ & $16.7 \%$ & $25 \%$ & $0 \%$ & $4.2 \%$ & $0 \%$ & $0 \%$ & $41.7 \%$ \\
Expulsions & $41.7 \%$ & $12.5 \%$ & $4.2 \%$ & $0 \%$ & $0 \%$ & $0 \%$ & $0 \%$ & $0 \%$ \\
Arrests & $25 \%$ & $8.3 \%$ & $0 \%$ & $4.2 \%$ & $4.2 \%$ & $0 \%$ & $8.3 \%$ & $0 \%$ \\
\hline
\end{tabular}

\section{Experimental task}

Before their scan, participants completed a personal profile to "introduce" themselves to other individuals who they may interact with during the scan task. Each profile consisted of the participant's photo, their first name, as well as four traits that they, their friends, their family members, or teachers would use to describe them (Fig. 1). After completing their own profile, participants were introduced to eight other players who they were told were also completing a scan visit and playing the same games (Fig. 1). In reality, the other players were confederates. Participants viewed the eight profiles and were instructed to do their best to remember each individual, because they may interact with them in an upcoming game. Given that the goal was to create a social scenario where participants would observe bullying, the other players were created to fit into social schemas related to individuals who may bully, who may be victims, and who were neutral. Four of the confederates were described with neutral traits, e.g., "steady," "casual"; two were described with victim traits, e.g., "shy," "nerdy"; and two were described with bully traits, e.g., "competitive," "demanding." Traits for each category were chosen from a broader pool of 140 traits, which were normed by 38 individuals ( 21 females; $\mathrm{M}_{\mathrm{age}}=23.55$ years) who were asked to rate the extent to which each item embodied bullies or victims ( 1 = "Victim trait"; 4 = "Neutral trait"; 7 $=$ "Bully trait"). Bully traits selected were those that received a mean rating of 5.5 or greater, and victim traits were those that received a mean rating of 2.5 or lower. Each bully and victim confederate were matched to be the same gender and ethnicity as the participant, with neutral profiles being gender-congruent but also including both ethnically congruent and incongruent partners (see Fig. 1 for example for white male participant). Profile photos were pulled from google image searches and other available photo databases containing photos of teenagers and young adults (Stanley et al., 2016).

After viewing the profiles, participants were instructed on how to play "the catch game" (Cyberball: Williams \& Jarvis, 2006) - an experimental paradigm used to simulate social inclusion and exclusion where participants throw a virtual ball to one another, although not necessarily in an egalitarian fashion (Masten, Morelli, \& Eisenberger, 2011). After learning the rules, each participant was assigned to play a selfpaced round with two of the neutral confederates, who were programmed to be egalitarian. Participants could see the photographs of the other two players on a computer screen as well as their own "hand" that they controlled using one of two buttons to indicate to whom they wanted to throw the ball. Across 48 ball tosses, the participant was equally included. Participants were instructed that the other six players also had been randomly assigned into two groups of three players who would be playing the game. 


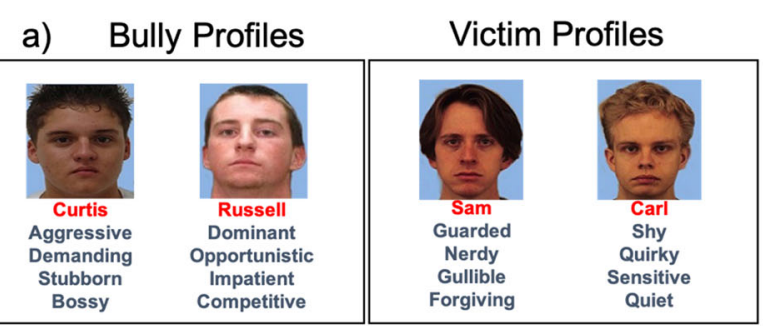

Neutral Profiles

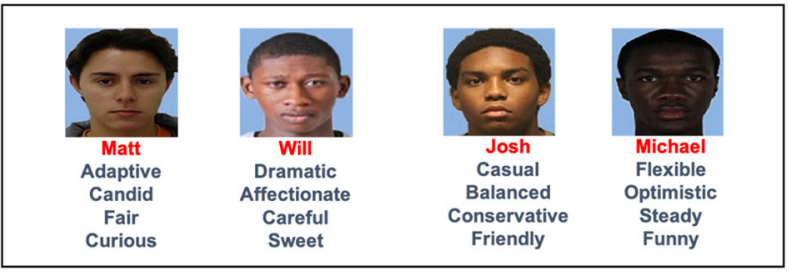

b) Social exclusion

c) Social inclusion

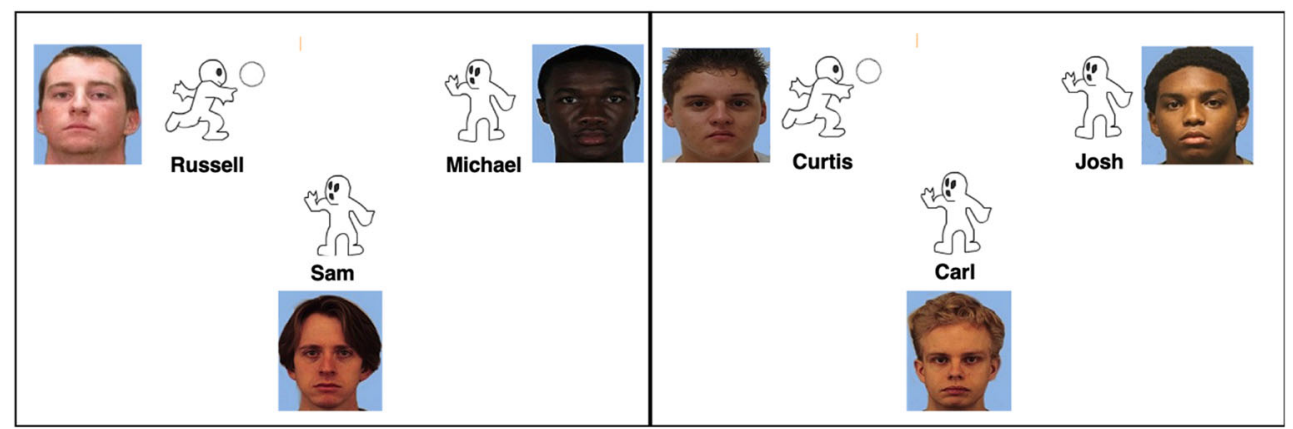

Fig. 1. Profiles of confederates (a), as well as randomly presented passive viewing of either social exclusion (b) or inclusion (c)

During the fMRI scan, participants were told that they would be observing the two rounds that the other six players had completed during their pre-scan session. They were first shown a screen with the profiles of the three players who they would be observing, and then they passively viewed the Cyberball games that were identical in length and number of throws to the pre-scan game that they played. Each round contained one confederate with bully traits, one with victim traits, and one neutral player. One of the rounds depicted social exclusion, where the bully confederate was preprogrammed to exclude the victim confederate while the neutral confederate sparingly threw the ball to the victim (only 4 times during the entire interaction). A second round depicted social inclusion during which the three players threw the ball to each other equally (Fig. 1). Run order of the exclusion/inclusion rounds was randomized between participants to reduce any effect of expectation violation.

\section{Illinois Bully Scale}

Participants completed the University of Illinois Bully Scale (IBS) to assess frequency of targeted aggressive behaviors (Espelage \& Holt, 2001). The types of bullying behaviors assessed by the 9-item scale included social exclusion, rumor spreading, name-calling, and unprovoked aggression. Participants used a 5-point Likert scale $(1=$ "Never," to $5=$ "7 or more times") to indicate the number of times they have engaged in bullying behaviors over the past 30 days. Example items include "I upset other students for the fun of it," and "I spread rumors about other students," with higher scores indicating a greater number of bullying behaviors. Importantly, the Bully Scale is theoretically distinct from Bully-Victim categorizations, distinguishing those who aggress in the context of power imbalances (e.g., bully) from those generally more inclined to aggress across situational contexts (Ybarra, Espelage, \& Mitchell, 2014). In our sample, there were no gender or race differences in bullying.

\section{Relationship of bullying to other psychological variables}

Given that bullying often is studied indirectly, or as a manifestation of other traits (van Geel, Goemans, Toprak, \& Vedder, 2017), we collected other measures to provide researchers with context when comparing our findings to others in the literature. In place of clinical interviews, we utilized commonly collected self-report measures of antisocial personality traits and other psychopathology. To assess for antisocial personality traits, we used the Short Dark Triad measure (SD3: Jones \& Paulhus, 2014) on a scale of 1 to 5 and the Comprehensive Assessment of Sadistic Tendencies measure (CAST: Buckels \& Paulhus, 2013) on a 
scale of 1 to 7. Additionally, we assessed for depression, using the Short Mood and Feelings Questionnaire (Angold, Costello, Messer, \& Pickles, 1995) on scale of 1 to 4, social anxiety using the Social Anxiety Scale (Franke \& Hymel, 1984) on a scale of 1 to 5, and sensation seeking using the Urgency, (lack of) Premeditation, (lack of) Perseverance, Sensation Seeking Impulsive Behavior Scale (UPPS: Whiteside \& Lynam, 2001) on a scale of 1 to 5 . All items from these measures were collected except for the CAST item asking if participants enjoyed harming their romantic partner during sex (see Table 2 for relationship of each trait to bullying).

\section{fMRI data acquisition}

Neuroimaging data were collected utilizing a 3 Tesla Siemens Trio MRI scanner. Our adapted Cyberball paradigm included T2*-weighted echoplanar images (EPI; slice thickness $=3 \mathrm{~mm}$; 38 slices; $\mathrm{TR}=2 \mathrm{~s} ; \mathrm{TE}=25 \mathrm{~ms} ; 92 \times 92$ matrix; FOV $=230 \mathrm{~mm}$; $2.5-x 2.5-x 3-\mathrm{mm}^{3}$ voxel size). The structural scans consisted of a T2* weighted, high resolution, matched-bandwidth (MBW) anatomical scan $(\mathrm{TR}=4 \mathrm{~s} ; \mathrm{TE}=64 \mathrm{~ms} ; \mathrm{FOV}=230 ; 192 \times 192$ matrix; slice thickness $=3 \mathrm{~mm} ; 38$ slices) and a $\mathrm{T} 1 *$ magnetization-prepared rapid-acquisition gradient echo $($ MPRAGE; TR $=1.9$ s; TE $=2.3 \mathrm{~ms} ; \mathrm{FOV}=230 ; 256 \times 256$ matrix; sagittal plane; slice thickness $=1 \mathrm{~mm} ; 192$ slices). The orientation of the MBW and EPI scans were set to be oblique axial to maximize brain coverage and reduce signal dropout.

\section{fMRI data processing and analysis}

Statistical Parametric Mapping was used to process and analyze the neuroimaging data (SPM8; Wellcome Department of Cognitive Neurology, Institute of Neurology, London, UK). In order to correct for head motion, spatial realignment was conducted during preprocessing of images. Realigned functional data were then coregistered to the high resolution MPRAGE image. The MPRAGE was segmented into cerebrospinal fluid (CSF), gray matter, and white matter. The normalization transformation matrix from the segmentation step was then applied to the functional and T2 structural images to transform them into standard stereotactic space as defined by the Montreal Neurological Institute and the International Consortium for Brain Mapping. An 8-mm Gaussian kernel, full-width-at-half maximum, was used to smooth the functional data, increasing signal-to-noise ratio. Each round of Cyberball was convolved with the canonical hemodynamic response function. High-pass temporal filtering with a cutoff of $128 \mathrm{~s}$ was applied to remove lowfrequency drift in the time-series. A restricted maximum likelihood algorithm was used to estimate serial autocorrelations with an autoregressive model order of 1 .

At the individual level, a fixed-effects analysis was modeled as a block design (social exclusion, social inclusion). The parameter estimates from the GLM were used to create linear contrast images comparing each of the conditions of interest at the group level. Random effects, whole brain analyses were conducted using GLMFlex to examine group effects of condition type on neural activation (http://mrtools. mgh.harvard.edu/index.php/GLM_Flex). We conducted whole-brain regression analyses in which each participant's self-reported bullying was regressed onto the contrast of interest (exclusion-inclusion). To correct for multiple comparisons, we conducted a Monte Carlo simulation using 3dClustSim while estimating smoothness with the $3 \mathrm{dFWHMx}$ function in the AFNI software package (Ward, 2000). Results of the $3 \mathrm{dCl}$ ustSim indicated a voxel-wise threshold of $p<0.005$ combined with a minimum cluster size of 76 contiguous voxels for the whole-brain analysis, corresponding to $p<0$. 05 FWE corrected.

Table 2 The relationship of bullying to other psychological variables

\begin{tabular}{|c|c|c|c|c|c|}
\hline Measure & $\begin{array}{l}\text { Mean } \\
(\mathrm{SD})\end{array}$ & Min & Max & $\alpha$ & $\begin{array}{l}r(p) \text { to Illinois Bully } \\
\text { Scale }\end{array}$ \\
\hline Illinois Bully Scale & $1.88(1.03)$ & 1.00 & 4.67 & .94 & ---------- \\
\hline Short Dark Triad: Psychopathy & $2.88(.71)$ & 1.44 & 3.78 & .71 & $.45(.03)$ \\
\hline Short Dark Triad: Narcissism & $3.18(.54)$ & 2.00 & 3.89 & .50 & $.02(.94)$ \\
\hline Short Dark Triad: Machiavellianism & $3.36(.85)$ & 1.44 & 4.89 & .79 & $.34(.10)$ \\
\hline Comprehensive Assessment of Sadistic Tendencies: Physical & $2.68(1.63)$ & 1.00 & 7.00 & .89 & $.30(.15)$ \\
\hline Comprehensive Assessment of Sadistic Tendencies: Verbal & $3.65(1.58)$ & 1.33 & 6.50 & .88 & $.37(.08)$ \\
\hline Comprehensive Assessment of Sadistic Tendencies: Vicarious & $3.62(1.35)$ & 1.29 & 6.43 & .81 & $.05(.83)$ \\
\hline $\begin{array}{l}\text { Urgency, Premeditation, Perseverance, Sensation Seeking Impulsivity Scale: Sensation } \\
\text { Seeking }\end{array}$ & $2.88(.61)$ & 1.75 & 4.00 & .85 & $-.14(.51)$ \\
\hline Short Mood and Feelings Questionnaire: Depressive Feelings & $1.98(.87)$ & 1.00 & 3.92 & .97 & $.28(.19)$ \\
\hline Social Anxiety Scale & $2.00(1.01)$ & 1.00 & 4.06 & .98 & $.29(.17)$ \\
\hline
\end{tabular}




\section{Brain results}

We first conducted whole-brain $t$-tests to examine the main effect of the task, comparing the contrast social exclusion > social inclusion. We did not find any significant patterns of activation to this contrast or to the opposite (social inclusion > social exclusion). Next, we examined how adolescents' endorsement of bullying correlated with neural activation during the social exclusion $>$ social inclusion contrast. We ran a whole-brain regression in which bullying scores were regressed onto neural activation. Several significant clusters were observed, with one large cluster connecting bilateral amygdala, ventral striatum, and insula and another including medial prefrontal cortex. As shown in Fig. 2, as individuals reported engaging in greater rates of bullying behaviors, we saw subsequent increases in activation when viewing social exclusion relative to inclusion (see Table 3 for full results).

\section{Discussion}

We examined delinquent youths' neural processing while observing peers being excluded, with a particular focus on how self-reported bullying related to neural activation patterns when observing others being bullied. By employing a passive viewing paradigm of social exclusion, we tested how a top-down motivational account (i.e., bullying serving as a social strategy attuned to social hierarchy) would relate to neural activation when viewing instances of social exclusion versus social inclusion. Adolescents who endorsed higher rates of bullying demonstrated higher relative activation in the ventral striatum, amygdala, medial prefrontal cortex, and insula while viewing social exclusion relative to inclusion. Activation in these regions, commonly associated with reward-learning, salience monitoring, and motivational processes, provides preliminary evidence that bullying is associated with increases in neural activation when observing a situation when social hierarchy cues were salient.
Table 3 Neural regions associated with activation differences when viewing social exclusion relative to inclusion

\begin{tabular}{|c|c|c|c|c|c|c|c|}
\hline Region & BA & & $\mathrm{x}$ & $\mathrm{y}$ & $\mathrm{z}$ & $\mathrm{t}$ & $\mathrm{k}$ \\
\hline \multicolumn{8}{|c|}{ Positive correlation with bullying } \\
\hline IFG & 47 & $\mathrm{R}$ & 33 & 23 & -14 & 5.75 & $1424^{\mathrm{a}}$ \\
\hline VS & & $\mathrm{L}$ & -9 & 8 & -11 & 3.69 & a \\
\hline VS & & $\mathrm{R}$ & 9 & 8 & -8 & 3.43 & a \\
\hline Insula & & $\mathrm{L}$ & -36 & 14 & 1 & 3.53 & $\mathrm{a}$ \\
\hline Insula & & $\mathrm{R}$ & 45 & 8 & -2 & 3.08 & a \\
\hline Amygdala & & $\mathrm{R}$ & 21 & 2 & -23 & 3.77 & a \\
\hline Fusiform & 37 & $\mathrm{R}$ & 30 & -25 & -29 & 3.61 & 197 \\
\hline Precentral Gyrus & 4 & $\mathrm{~L}$ & -39 & -28 & 67 & 5.27 & 213 \\
\hline Precuneus & 7 & $\mathrm{R}$ & 12 & 70 & 58 & 5.12 & 163 \\
\hline MPFC & $9 / 10$ & $\mathrm{~L}$ & -9 & 62 & 4 & 5.10 & 248 \\
\hline Precentral Gyrus & 4 & $\mathrm{R}$ & 36 & -13 & 55 & 4.81 & 217 \\
\hline PCC & 31 & $\mathrm{~L}$ & -6 & -25 & 55 & 4.56 & 135 \\
\hline \multicolumn{8}{|c|}{ Negative correlation with bullying } \\
\hline Fusiform & 37 & $\mathrm{R}$ & 17 & -65 & -10 & 3.01 & 578 \\
\hline Mid occipital cortex & 18 & $\mathrm{R}$ & 21 & -97 & 10 & 3.33 & 145 \\
\hline Cuneus & & & 0 & -88 & 28 & 5.10 & $226^{\mathrm{b}}$ \\
\hline Mid occipital cortex & 18 & $\mathrm{~L}$ & -15 & -97 & 10 & 2.93 & $\mathrm{~b}$ \\
\hline
\end{tabular}

$R$ right; $L$ left. $\mathrm{x}, \mathrm{y}$, and $\mathrm{z}$ refer to MNI coordinates; $t, t$-score at those coordinates (local maxima); IFG inferior frontal gyrus; $V S$ ventral striatum; $M P F C$ medial prefrontal cortex; $P C C$ posterior cingulate cortex

Regions that share the same superscript are part of the same cluster

The amygdala, while implicated as a region for processing affective resonance (Marsh et al., 2014), also has been implicated in processing motivationally relevant stimuli more generally (Cunningham \& Brosch, 2012; Ernst, Pine, \& Hardin, 2006; Stillman, Van Bavel, \& Cunningham, 2015). The ventral striatum is linked with reward processing (Knutson, Fong, Adams, Varner, \& Hommer, 2001), and more comprehensive accounts consider both of these regions as part of a network that functionally identifies salient information in one's environment (Stillman et al., 2015; Zink et al., 2003). Given our experimental design,

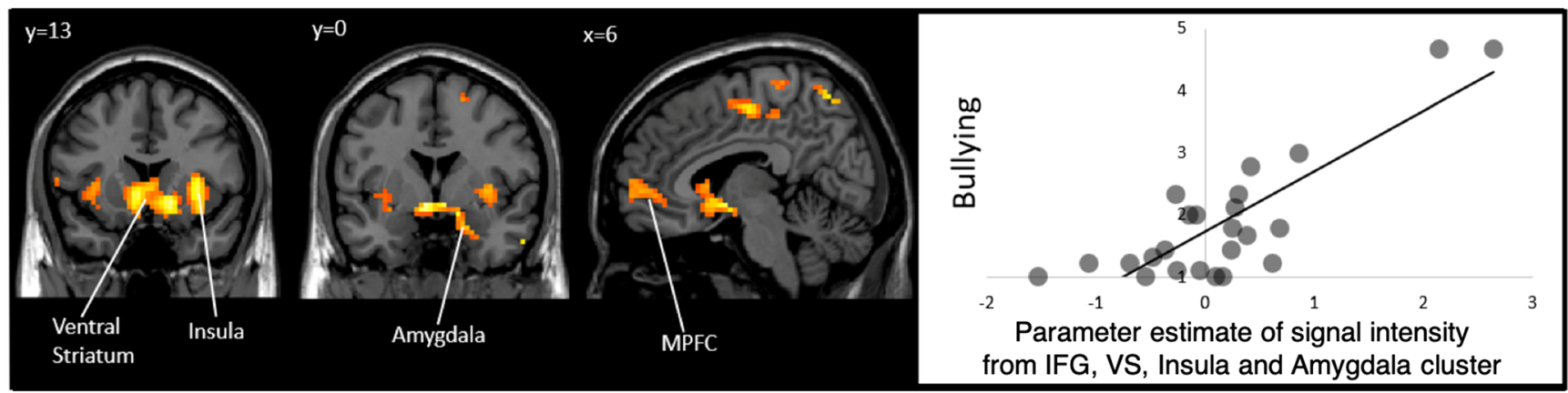

Fig. 2. Greater endorsement of bullying behaviors was associated with greater activation during social exclusion $>$ social inclusion in the ventral striatum, insula, amygdala, and medial prefrontal cortex. For descriptive purposes, parameter estimates of signal intensity were extracted from the contiguous cluster including the IFG, VS, insula and amygdala and plotted against adolescents' self-reported bullying (right panel) (When removing the two highest bully scores, we continue to observe significant activation in th cluster, indicating that these participants are not uniquely driving the result.). $\mathrm{mPFC}$ scatterplot not shown 
considering amygdala and striatal activation as markers of salient environmental cues also aligns with the activation observed in the insula, because this structure also is consistently implicated in salience monitoring (Menon \& Uddin, 2010). The medial prefrontal cortex is implicated in a diverse set of psychological functions, ranging from reward valuation (Carlson, Foti, Mujica-Parodi, Harmon-Jones, \& Hajcak, 2011) to viewing negative emotional stimuli (Etkin, Egner, \& Kalisch, 2011). Taking a more comprehensive approach, the activation patterns that we observed in the mPFC, insula, and amygdala have been cited as hubs of a sociomoral reasoning circuit (Decety \& Cowell, 2014). In particular, the medial prefrontal cortex has been implicated in the interpretation of mental states (Gusnard, Akbudak, Shulman, \& Raichle, 2001) and the ventral medial prefrontal cortex in moral computations (Decety, Michalska, \& Kinzler, 2012). Given that both positive or negative interpretations are possible responses in our task (i.e., viewing others being excluded may theoretically be interpreted as aversive or rewarding), we are hesitant to speculate about what type of psychological process is being evoked given our specific experimental manipulation and passive viewing paradigm.

Much of the past research has found deficient processing (e.g., hypoactivation) and lack of responsivity to socioaffective cues in aggressive populations (Blair et al., 2016; Marsh, 2016), where the presumed inability of aggressive individuals to recognize social and affective cues has been thought to be key in explaining the connection to aggressive behaviors (Blair, 2005; Blair, Jones, Clark, \& Smith, 1997; Marsh et al., 2008; Marsh et al., 2013). However, a number of findings challenge this mechanistic account, both by focusing on the interplay between attention and motivation processes, and by considering the efficacy of empathy interventions. First, evidence has been accumulating that malevolent motivations focus attentional resources toward social cues (Paulhus, Curtis, \& Jones, 2018), like physical cues indicating past victimization (Book, Costello, \& Camilleri, 2013; Denardo Roney, Falkenbach, \& Aveson, 2018; Ritchie, Blais, Forth, \& Book, 2018; Wheeler, Book, \& Costello, 2009), personal descriptions of oneself as vulnerable (Wilson, Demetrioff, \& Porter, 2008), and verbal cues of dominance (Book, Quinsey, \& Langford, 2007). Second, the evidence that improving offender empathy has long lasting, meaningful positive effects on antisocial behavior is quite limited (Merrell, Juskelis, Tran, \& Buchanan, 2008; Yeager, Fong, Lee, \& Espelage, 2015). Whereas empathic dysfunction (e.g., decreased theory of mind or affective simulation) was a logical starting point to examine the etiology of bullying and other aggressive behaviors, the need to examine antisocial motivations beyond callousness is empirically supported (Vachon \& Lynam, 2016). This does not mean that empathy has no relationship to aggression; however, it is likely overstated. The relationship of empathy to aggression is small and likely moderated by age (Yeager et al., 2015); perhaps this is due to still-maturing neural circuitry (Lee, Perino, McElwain, \& Telzer, 2019), because empathic deficits show extremely small, often nonsignificant relationships to aggression in older populations (Vachon, Lynam, \& Johnson, 2013).

Bullying was associated with hyperactivation in the ventral striatum, insula, and amygdala; perhaps, hypoactivation in past studies occurs, because aggressive offenders may not always be motivated to process such cues (Jordan, Amir, \& Bloom, 2016). For instance, when examining neural responsivity to viewing others in pain, psychopathy was originally associated with reduced neural reactivity in pain-processing regions (Meffert, Gazzola, Den Boer, Bartels, \& Keysers, 2013); however, when the same participants were instructed to feel with the actors being hurt, neural hyposensitivity was attenuated. Perhaps hypoactivation does not reflect an inability or deficiency but rather an unwillingness or lack of automaticity to process pain in others. Accounts relying on hypoactivation of affective regions in aggression may be conflating "deficiency" of the empathic response with a mismatched antisocial motivation. The assumption that youth engaging in higher rates of bullying are unaware of the negative consequences of their aggressive actions may be inaccurate, because it fails to adequately account for motivational factors (Zaki, 2014).

Aggression stemming from socially dissonant responsese.g., taking pleasure in others' pain or expressing displeasure when seeing others' happiness - is more explanatory than traditional empathic explanations (Vachon \& Lynam, 2016). Understanding how these antisocial individual differences interact with situational context is imperative for increasing prosocial decision-making (Weisz \& Zaki, 2018). Those who bully may be focused on cues and situations relevant for understanding and taking advantage of social hierarchies and maintaining or gaining status within such hierarchies (Volk et al., 2014), explaining why interventions teaching "prosocial ways to gain status" may be particularly useful tools to combat bullying (Ellis, Volk, Gonzalez, \& Emry, 2016; Yeager, Dahl, \& Dweck, 2018). Exploring how situational contexts (Ibáñez \& García, 2018) impact socioaffective processing echoes much of what has been called for by bullying (Espelage, 2015), psychopathology (Cuthbert \& Insel, 2010), and neuroscience (Krakauer et al., 2017) experts.

Our task shows how social neuroscience techniques can play a role in elucidating how specific destructive behaviors are evoked within social contexts. We focused specifically on how self-reported bullying relates to neural processing of a vulnerable conspecific being socially excluded by a dominant conspecific. Our results show that bullying relates to heightened activation in neural regions associated with motivation and salience when viewing such circumstances, suggesting that when considering why individuals engage in such acts, a lack of socioemotional awareness on behalf of the perpetrator may be unwarranted. Instead, these findings highlight the role that social interventions may be able to play: if bullies are aware of what they are doing, then moving away from perceived "deficiencies" and instead devoting resources to studying the system level buffers that 
may push individuals toward or away from aggressing is crucial (Salmivalli, Voeten, \& Poskiparta, 2011; Thornberg \& Wänström, 2018). Social components, such as classroom culture, adult supervision, or intervening classmates, can help to mitigate the worst expressions of bullying (Chan, Hollingsworth, Espelage, \& Mitchell, 2016) but have not been examined via neuroscience paradigms. Such information will provide clinicians, school officials, and parents with valuable information potentially useful for stemming the worse outcomes associated with bullying perpetration and interpreting the effects of future interventions.

While the results of this study are consistent with much recent work, there are a number of constraints on generalizability that will need to be addressed in future inquiries. First, our sample size is small and the participants were selected on confirmable delinquency, which limits the generalizability of bullying to more normative contexts. As we have highlighted, the lack of explicit focus on bullying has limited the research base available for gleaning insights and is in much need of increased scholarship from multiple perspectives to make it more representative at the population level. Second, we were unable to collect standardized assessments of intelligence (e.g., WAIS: Kaufman \& Lichtenberger, 1999) and socioemotional intelligence (e.g., MSCEIT: Mayer, 2002). Third, our modified Cyberball paradigm is not a perfect analogue to actively bullying a person in vivo and is more reflective of observing someone else being bullied. We focused on "viewing bullying" rather than actively bullying others due to the paucity of tasks reflective of that process in an ecologically valid fashion using fMRI. Future research should explore interactions of social factors (e.g., appearance, gender, reputations) and examine how the neural activation observed when processing social cues relevant to bullying relates to specific types of antisocial behavior in future interactions (e.g., such as those in an iterative economic game; King-Casas \& Chiu, 2012; Sharp, 2012).

Examining aggression that occurs in the context of successfully processing social information, rather than as a result of incorrectly reading the situation or emotions of others, signifies a change that researchers and clinicians alike need to explore. While preliminary, our study adds to a body of literature, suggesting that bullying may best be understood as the end result of a societally undesirable — but perhaps effectiveinterpersonal strategy, driven not by deficiency but by motivational factors. Our work suggests research into bullying may need to be incorporate a diverse approach (Espelage \& Swearer, 2003), employing a varied set of methods and perspectives to truly understand what drives, and eventually what can reduce, the phenomenon.

Acknowledgments The authors thank the members of the Developmental Social Neuroscience Lab at the University of North Carolina, Chapel-Hill and the Biomedical Imaging Center at the University of Illinois, UrbanaChampaign for their help and support on the project. They also extend thanks to the schools, administrators, and counselors who helped with recruitment of participants for this project.

Funding This manuscript was partially supported by grants from the National Science Foundation (NSF SES 1459719 to E.H.T. \& NSF Graduate Fellowship 2016220797 to J.F.G.M.), the National Institutes of Health (R01DA039923 to E.H.T.), the National Institutes of Mental Health (NIMH 2T32MH100019-06 to J.L.L), and generous funds from the Department of Psychology at the University of Illinois.

\section{Compliance with ethical standards}

Conflict of interest All authors report no biomedical financial interests or potential conflicts of interest.

Neuroimaging data have been uploaded to neurovault (https://neurovault. org/collections/4482/).

\section{References}

Alcock, J. (1989). Animal behavior. Sunderland, MA: Sinauer Associates.

Angold, A., Costello, E.J., Messer, S.C., \& Pickles, A. (1995). Development of a short questionnaire for use in epidemiological studies of depression in children and adolescents. International Journal of Methods in Psychiatric Research, 5(4), 237-249.

Baams, L., Talmage, C.A., \& Russell, S.T. (2017). Economic costs of bias-based bullying. School Psychology Quarterly, 32(3), 422-433. https://doi.org/10.1037/spq0000211

Balcetis, E., \& Dunning, D. (2006). See what you want to see: Motivational influences on visual perception. Journal of Personality and Social Psychology, 91(4), 612-625. https://doi.org/ 10.1037/0022-3514.91.4.612

Bender, D., \& Lösel, F. (2011). Bullying at school as a predictor of delinquency, violence and other anti-social behaviour in adulthood. Criminal Behaviour and Mental Health, 21(2), 99-106. https://doi. org/10.1002/cbm.799

Berger, K.S. (2007). Update on bullying at school: Science forgotten? Developmental Review, 27(1), 90-126. https://doi.org/10.1016/j.dr. 2006.08.002

Bjorklund, D., \& Hawley, P.H. (2014). Aggression grows up: Looking through an evolutionary developmental lens to understand the causes and consequences of human aggress. In Shackelford, T.K. \& Hansen, R.D. (eds.) The evolution of violence (pp. 159-186). New York, NY: Springer.

Blair, R.J.R. (2005). Responding to the emotions of others: Dissociating forms of empathy through the study of typical and psychiatric populations. Consciousness and Cognition, 14(4), 698-718. https://doi. org/10.1016/j.concog.2005.06.004

Blair, R.J.R., Jones, L., Clark, F., \& Smith, M. (1997). The psychopathic individual: A lack of responsiveness to distress cues? Psychophysiology, 34, 192-198. https://doi.org/10.1111/j.14698986.1997.tb02131.x

Blair, R.J.R., Veroude, K., \& Buitelaar, J.K. (2016). Neuro-cognitive system dysfunction and symptom sets: A review of fMRI studies in youth with conduct problems. Neuroscience \& Biobehavioral Reviews. https://doi.org/10.1016/j.neubiorev.2016.10.022

Book, A., Costello, K., \& Camilleri, J.A. (2013). Psychopathy and victim selection: The use of gait as a cue to vulnerability. Journal of Interpersonal Violence, 28(11), 2368-2383. https://doi.org/10. $1177 / 0886260512475315$ 
Book, A., Quinsey, V.L., \& Langford, D. (2007). Psychopathy and the perception of affect and vulnerability. Criminal Justice and Behavior, 34(4), 531-544. https://doi.org/10.1177/ 0093854806293554

Book, A.S., Volk, A.A., \& Hosker, A. (2012). Adolescent bullying and personality: An adaptive approach. Personality and Individual Differences, 52(2), 218-223. https://doi.org/10.1016/j.paid.2011. 10.028

Bromberg-Martin, E.S., Matsumoto, M., \& Hikosaka, O. (2010). Dopamine in motivational control: Rewarding, aversive, and alerting. Neuron, 68(5), 815-834. https://doi.org/10.1016/j.neuron. 2010.11.022

Buckels, E. E., \& Paulhus, D. L. (2013). Comprehensive assessment of sadistic tendencies (CAST). Unpublished measure, University of British Columbia.

Caldwell, J.Z., Armstrong, J.M., Hanson, J.L., Sutterer, M.J., Stodola, D.E., Koenigs, M., Kalin, N.H., Essex, M.J. \& Davidson, R.J. (2015). Preschool externalizing behavior predicts gender-specific variation in adolescent neural structure. PloS One, 10(2), e0117453. https://doi.org/10.1371/journal.pone.0117453

Carlson, J.M., Foti, D., Mujica-Parodi, L.R., Harmon-Jones, E., \& Hajcak, G. (2011). Ventral striatal and medial prefrontal BOLD activation is correlated with reward-related electrocortical activity: A combined ERP and fMRI study. Neuroimage, 57(4), 1608-1616. https://doi.org/10.1016/j.neuroimage.2011.05.037

Center for Disease Control (2016). Understanding Bullying Fact Sheet 2016. https://www.cdc.gov/violenceprevention/pdf/bullying factsheet.pdf

Chan, W.Y., Hollingsworth, M.A., Espelage, D.L., \& Mitchell, K.J. (2016). Preventing violence in context: The importance of culture for implementing systemic change. Psychology of Violence, 6(1), 22-26. https://doi.org/10.1037/vio0000021

Copeland, W.E., Wolke, D., Angold, A., \& Costello, E.J. (2013). Adult psychiatric outcomes of bullying and being bullied by peers in childhood and adolescence. JAMA Psychiatry, 70(4), 419-426. doi: https://doi.org/10.1001/jamapsychiatry.2013.504

Cunningham, W.A., \& Brosch, T. (2012). Motivational salience: Amygdala tuning from traits, needs, values, and goals. Current Directions in Psychological Science, 21(1), 54-59. https://doi.org/ 10.1177/0963721411430832

Cuthbert, B., \& Insel, T. (2010). The data of diagnosis: New approaches to psychiatric classification. Psychiatry, 73(4), 311-314. https://doi. org/10.1521/psyc.2010.73.4.311

Decety, J., \& Cowell, J.M. (2014). Friends or foes: Is empathy necessary for moral behavior?. Perspectives on Psychological Science, 9(5), 525-537. https://doi.org/10.1177/1745691614545130

Decety, J., Michalska, K.J., \& Kinzler, K.D. (2012). The contribution of emotion and cognition to moral sensitivity: A neurodevelopmental study. Cerebral Cortex, 22, 209-220. https://doi.org/10.1093/cercor/ bhr111

Denardo Roney, J.L., Falkenbach, D.M., \& Aveson, O. (2018). Psychopathy and victim selection: Does nonverbal decoding or empathy impact vulnerability ratings?. Journal of Interpersonal Violence, 0886260517742914. https://doi.org/10.1177/ 0886260517742914

Dodge, K.A., \& Albert, D. (2012). Evolving science in adolescence. Developmental Psychology, 48(3), 624-627. https://doi.org/10. 1037/a0027683

Dodge, K.A. Lochman, J.E., Harnish, J.D., Bates, J.E. \& Pettit G.S. (1997) Reactive and proactive aggression in school children and psychiatrically impaired chronically assaultive youth. Journal of Abnormal Psychology, 106, 37-51. https://doi.org/10.1037/0021843X.106.1.37

Ellis, B.J., \& Bjorklund, D.F. (2012). Beyond mental health: An evolutionary analysis of development under risky and supportive environmental conditions: an introduction to the special section.
Developmental Psychology, 48(3), 591-597. https://doi.org/10. 1037/a0027651

Ellis, B.J., Del Giudice, M., Dishion, T.J., Figueredo, A.J., Gray, P., Griskevicius, V., Hawley, P.H., Jacobs, W.J., Volk, A.A., \& Wilson, D.S. (2012). The evolutionary basis of risky adolescent behavior: Implications for science, policy, and practice. Developmental Psychology, 48(3), 598-623. https://doi.org/10. 1037/a0026220

Ellis, B.J., Volk, A.A., Gonzalez, J.M., \& Emry, D.D. (2016). The meaningful roles intervention: An evolutionary approach to reducing bullying and increasing prosocial behavior. Journal of Research in Adolescence, 26, 622-637. https://doi.org/10.1111/jora.12243

Ernst, M., Pine, D.S., \& Hardin, M. (2006). Triadic model of neurobiology of motivated behavior in adolescence. Psychological Medicine, 36(3), 299-312. https://doi.org/10.1017/S0033291705005891

Espelage, D. (2015). Data needs for emerging research issues in bully and violence prevention: Strengths and limitations of the national center for educational statistics data sets. AERA Open, 1(3), 1-7. https:// doi.org/10.1177/2332858415604147

Espelage, D.L., \& Holt, M.K. (2001). Bullying and victimization during early adolescence: Peer influences and psychosocial correlates. Journal of Emotional Abuse, 2(2-3), 123-142. https://doi.org/10. $1300 / \mathrm{J} 135 \mathrm{v} 02 \mathrm{n} 0208$

Espelage, D.L., \& Swearer, S.M. (2003). Research on school bullying and victimization: What have we learned and where do we go from here?. School psychology review, 32(3), 365-384.

Etkin, A., Egner, T., \& Kalisch, R. (2011). Emotional processing in anterior cingulate and medial prefrontal cortex. Trends in Cognitive Sciences, 15(2), 85-93. https://doi.org/10.1016/j.tics.2010.11.004

Farrell, A.H., Della Cioppa, V., Volk, A.A., \& Book, A.S. (2014). Predicting bullying heterogeneity with the HEXACO model of pesonality. International Journal of Advances in Psychology, 3(2), 30-39. https://doi.org/10.14355/ijap.2014.0302.02

Figueredo, A.J., \& Jacobs, W.J. (2010). Aggression, risk-taking, and alternative life history strategies: The behavioral ecology of social deviance. In M. Frias-Armenta \& V. Corral-Verdugo (Eds.), Biopsychosocial perspectives on interpersonal violence (pp. 3-27). Hauppauge, NY: Nova Science Publishers.

Franke, S., \& Hymel, S. (1984). Social anxiety in children: The development of self-report measures. In Biennial meeting of the University of Waterloo conference on child development, Waterloo, Ontario, Canada.

Gantman, A.P., \& Van Bavel, J.J. (2015). Moral perception. Trends in Cognitive Sciences, 19(11), 631-633. https://doi.org/10.1016/j.tics. 2015.08.004

Gao, Y., \& Raine, A. (2010). Successful and unsuccessful psychopaths: A neurobiological model. Behavioral Sciences \& the Law, 28(2), 211223. https://doi.org/10.1002/bsl.924

Garandeau, C.F., \& Lansu, T.A. (2019). Why does decreased likeability not deter adolescent bullying perpetrators?. Aggressive Behavior, 112. https://doi.org/10.1002/ab.21824

Gladden, R.M., Vivolo-Kantor, A.M., Hamburger, M.E., \& Lumpkin, C.D. (2014). Bullying surveillance among youths: Uniform definitions for public health and recommended data elements. Version 1.0. Centers for Disease Control and Prevention. Retrieved from https:// eric.ed.gov/?id=ED575477

Goodall, J. (1986). The chimpanzees of Gombe: Patterns of behavior. Cambridge, MA: Belknap Press.

Gusnard, D.A., Akbudak, E., Shulman, G.L., \& Raichle, M.E. (2001). Medial prefrontal cortex and self-referential mental activity: Relation to a default mode of brain function. Proceedings of the National Academy of Sciences, 98(7), 4259-4264. https://doi.org/ 10.1073/pnas.071043098

Hawley, P.H. (1999). The ontogenesis of social dominance: A strategybased evolutionary perspective. Developmental Review, 19(1), 97132. https://doi.org/10.1006/drev.1998.0470 
Hawley, P.H. (2011). The role of competition and cooperation in shaping personality: An evolutionary perspective on social dominance, Machiavellianism, and children's social development. In Buss, D.M., \& Hawley, P.H. (Eds.). The evolution of personality and individual differences (pp. 61-85). New York, NY. Oxford University Press.

Hawley, P.H., Little, T.D., \& Card, N.A. (2007). The allure of a mean friend: Relationship quality and processes of aggressive adolescents with prosocial skills. International Journal of Behavioral Development, 31(2), 170-180. https://doi.org/10.1177/ 0165025407074630

Hawley, P.H., Stump, K.N., \& Ratliff, J.M. (2011). Sidestepping the jingle fallacy: Bullying, aggression, and the importance of knowing the difference. In D.L. Espelage \& S. Swearer (Eds.), Bullying in North American Schools (pp. 101-115). New York, NY: Taylor \& Francis.

Hyde, L.W., Shaw, D.S., \& Hariri, A.R. (2013). Understanding youth antisocial behavior using neuroscience through a developmental psychopathology lens: Review, integration, and directions for research. Developmental Review, 33(3), 168-223. https://doi.org/10. 1016/j.dr.2013.06.001

Ibáñez, A., \& García, A.M. (2018). Context as a determinant of interpersonal processes: The social context network model. In: Ibáñez, A., \& García, A. M (eds.) Contextual cognition (p 7-27). Springer, Cham. https://doi.org/10.1007/978-3-319-77285-1_2

Jones, D.N., \& Paulhus, D.L. (2014). Introducing the Short Dark Triad (SD3): A brief measure of dark personality traits. Assessment, 21(1), 28-41. https://doi.org/10.1177/1073191113514105

Jordan, M.R., Amir, D., \& Bloom, P. (2016). Are empathy and concern psychologically distinct?. Emotion, 16(8), 1107-1116. https://doi. org/10.1037/emo0000228

Juvonen, J., Graham, S., \& Schuster, M.A. (2003). Bullying among young adolescents: The strong, the weak, and the troubled. Pediatrics, 112(6), 1231-1237. https://doi.org/10.1542/peds.112.6. 1231

Juvonen, J., \& Ho, A.Y. (2008). Social motives underlying antisocial behavior across middle school grades. Journal of Youth and Adolescence, 37(6), 747-756. https://doi.org/10.1007/s10964-0089272-0

Kaufman, A.S., \& Lichtenberger, E.O. (1999). Essentials of WAIS-III assessment. John Wiley \& Sons Inc.

Kaukiainen A., Bjorkqvist K., Lagerspetz K., Osterman K., Salmivalli C., Rothberg S., \& Ahlbom, A. (1999). The relationships between social intelligence, empathy, and three types of aggression. Aggressive Behavior, 25, 81-89. https://doi.org/10.1002/(SICI)10982337(1999)25:2\%3C81::AID-AB1\%3E3.0.CO;2-M

King-Casas, B., \& Chiu, P.H. (2012). Understanding interpersonal function in psychiatric illness through multiplayer economic games. Biological psychiatry, 72(2), 119-125. https://doi.org/10.1016/j. biopsych.2012.03.033

Knutson, B., Fong, G.W., Adams, C.M., Varner, J.L., \& Hommer, D. (2001). Dissociation of reward anticipation and outcome with event-related fMRI. NeuroReport, 12(17), 3683- 3687. https://doi. org/10.1097/00001756-200112040-00016

Krakauer, J.W., Ghazanfar, A.A., Gomez-Marin, A., Maciver, M.A., \& Poeppel, D. (2017). Neuroscience needs behavior: Correcting a reductionist bias. Neuron, 93(3), 480-490. https://doi.org/10.1016/j. neuron.2016.12.041

Lamm, C., Decety, J., \& Singer, T. (2011). Meta-analytic evidence for common and distinct neural networks associated with directly experienced pain and empathy for pain. Neuroimage, 54(3), 2492-2502. https://doi.org/10.1016/j.neuroimage.2010.10.014

Lee, T.H., Perino, M.T., McElwain, N.L., \& Telzer, E.H. (2019). Perceiving facial affective ambiguity: A behavioral and neural comparison of adolescents and adults. Emotion. Advance online publication. https://doi.org/10.1037/emo0000558
Little, T., Brauner, J., Jones, S., Nock, M., \& Hawley, P.H. (2003). Rethinking aggression: A typological examination of the functions of aggression. Merrill-Palmer Quarterly, 49(3), 343-369. Retrieved from http://www.jstor.org/stable/23096059

MacDonald, G., \& Jensen-Campbell, L.A. (Eds.). (2011). Social pain: Neuropsychological and health implications of loss and exclusion. Washington, DC: American Psychological Association. https://doi. org/10.1037/12351-000

Mancilla-Caceres, J.F., Espelage, D., \& Amir, E. (2015). A computer game-based method for studying bullying and cyberbullying. Journal of school violence, 14(1), 66-86. https://doi.org/10.1080/ 15388220.2014 .963593

Maner, J.K. (2017). Dominance and prestige: A tale of two hierarchies. Current Directions in Psychological Science, 26(6), 526-531. https://doi.org/10.1177/0963721417714323

Marsh, A.A. (2016). Understanding amygdala responsiveness to fearful expressions through the lens of psychopathy and altruism. Journal of Neuroscience Research, 94(6), 513-525. https://doi.org/10.1002/ jnr.23668

Marsh, A.A., Finger, E.C., Fowler, K.A., Adalio, C.J., Jurkowitz, I.T.N., Schechter, J.C., Pine, D.S., Decety, J., \& Blair, R.J.R. (2013). Empathic responsiveness in amygdala and anterior cingulate cortex in youths with psychopathic traits. Journal of Child Psychology and Psychiatry, 54(8), 900-910. https://doi.org/10.1111/jcpp.12063

Marsh, A.A., Finger, E.C., Mitchell, D.G.V, Reid, M.E., Sims, C., Kosson, D.S., Towbin, K.E., Liebenluft, E., Pine, D.S. \& Blair, R.J.R. (2008). Reduced amygdala response to fearful expressions in children and adolescents with callous-unemotional traits and disruptive behavior disorders. American Journal of Psychiatry, 165(6), 712-720. https://doi.org/10.1176/appi.ajp.2007.07071145

Marsh, A.A., Stoycos, S.A., Brethel-Haurwitz, K.M., Robinson, P., VanMeter, J.W., \& Cardinale, E.M. (2014). Neural and cognitive characteristics of extraordinary altruists. Proceedings of the National Academy of Sciences of the United States of America, 111(42), 15036-41. https://doi.org/10.1073/pnas.1408440111

Masten, C.L., \& Eisenberger, N.I. (2009). Exploring the experience of social rejection in adults and adolescents: A social cognitive neuroscience perspective. In M.J. Harris (Ed.), Bullying, rejection, \& peer victimization (pp. 53-78). New York, NY: Springer Publishing Company.

Masten, C.L., Morelli, S.A., \& Eisenberger, N.I. (2011). An fMRI investigation of empathy for "social pain" and subsequent prosocial behavior. NeuroImage, 55(1), 381-388. https://doi.org/10.1016/j. neuroimage.2010.11.060

Masure, R.H., \& Allee, W. (1934). The social order in flocks of the common chicken and the pigeon. The Auk, 51(3), 306-327. doi: https://doi.org/10.2307/4077659

Mayer, J.D. (2002). MSCEIT: Mayer-Salovey-Caruso emotional intelligence test. Toronto, Canada: Multi-Health Systems.

Meffert, H., Gazzola, V., Den Boer, J.A., Bartels, A.A., \& Keysers, C. (2013). Reduced spontaneous but relatively normal deliberate vicarious representations in psychopathy. Brain, 136(8), 2550-2562. https://doi.org/10.1093/brain/awt190

Menon, V., \& Uddin, L.Q. (2010). Saliency, switching, attention and control: A network model of insula function. Brain Structure and Function, 1-13. https://doi.org/10.1007/s00429-010-0262-0

Merrell, K.W., Juskelis, M.P., Tran, O.K., \& Buchanan, R. (2008). Social and emotional learning in the classroom: Evaluation of strong kids and strong teens on students' social emotional knowledge and symptoms. Journal of Applied School Psychology, 24(2), 209-224. https://doi.org/10.1080/15377900802089981

Mills, K.L., Lalonde, F., Clasen, L.S., Giedd, J.N., \& Blakemore, S.J. (2014). Developmental changes in the structure of the social brain in late childhood and adolescence. Social Cognitive and Affective Neuroscience, 9(1), 123-131. https://doi.org/10.1093/scan/nss113 
Olweus, D. (2003). A profile of bullying at school. Educational Leadership, 60(6), 12-17.

Paulhus, D.L., Curtis, S.R., \& Jones, D.N. (2018). Aggression as a trait: The Dark Tetrad alternative. Current opinion in psychology, 19, 8892. https://doi.org/10.1016/j.copsyc.2017.04.007

Pederson, A.K., King, J.E., \& Landau, V.I. (2005). Chimpanzee (Pan troglodytes) personality predicts behavior. Journal of Research in Personality, 39(5), 534-549. https://doi.org/10.1016/j.jrp.2004.07. 002

Phillips, R. (2012). The financial costs of bullying, violence and vandalism. Proceedings of the National Association of Secondary School Principals, 28-29.

Rai, T.S., \& Fiske, A.P. (2012). Beyond harm, intention, and dyads: Relationship regulation, virtuous violence, and metarelational morality. Psychological Inquiry, 23(2), 189-193. https://doi.org/10. 1080/1047840X.2012.670782

Raine, A., Yang, Y., Narr, K.L., \& Toga, A.W. (2011). Sex differences in orbitofrontal gray as a partial explanation for sex differences in antisocial personality. Molecular Psychiatry, 16(2), 227-236. doi: https://doi.org/10.1038/mp.2009.136

Ritchie, M.B., Blais, J., Forth, A.E., \& Book, A.S. (2018) Identifying vulnerability to violence: the role of psychopathy and gender, Journal of Criminal Psychology, 8(2), 125-137. https://doi.org/10. 1108/JCP-06-2017-0029

Robers, S., Zhang, J., Truman, J., \& Snyder, T.D. (2010). Indicators of school crime and safety: 2010. Retrieved from https://nces.ed.gov/ pubs2011/2011002.pdf

Rose, A.J., Swenson, L.P., \& Waller, E.M. (2004). Overt and relational aggression and perceived popularity: Developmental differences in concurrent and prospective relations. Developmental Psychology, 40(3), 378-387. doi:https://doi.org/10.1037/0012-1649.40.3.378

Salmivalli, C., Voeten, M., \& Poskiparta, E. (2011). Bystanders matter: Associations between reinforcing, defending, and the frequency of bullying behavior in classrooms. Journal of Clinical Child \& Adolescent Psychology, 40(5), 668-676. https://doi.org/10.1080/ 15374416.2011.597090

Sebastian, C.L., Tan, G.C.Y., Roiser, J.P., Viding, E., Dumontheil, I., \& Blakemore, S.J. (2011). Developmental influences on the neural bases of responses to social rejection: Implications of social neuroscience for education. NeuroImage, 57(3), 686-694. https://doi.org/ 10.1016/j.neuroimage.2010.09.063

Sharp, C. (2012). The use of neuroeconomic games to examine social decision making in child and adolescent externalizing disorders. Current Directions in Psychological Science, 21(3), 183-188. https://doi.org/10.1177/0963721412444726

Sharp, C., Carolyn, H.A., \& Fonagy, P. (2011). Get them before they get you: Trust, trustworthiness, and social cognition in boys with and without externalizing behavior problems. Development and Psychopathology, 23(2), 647-658. doi:https://doi.org/10.1017/ S0954579410000003

Stanley, D.A., Sokol-Hessner, P., Fareri, D.S., Perino, M.T., Delgado, M.R., Banaji, M.R., \& Phelps, E.A. (2016). Race and reputation: Perceived racial group trustworthiness influences the neural correlates of trust decisions. Philosophical Transactions of The Royal Society: B, 367(1589), 744-753. doi:https://doi.org/10.1098/rstb. 2011.0300

Stickle, T.R., Kirkpatrick, N.M., \& Brush L.N. (2009). Callousunemotional traits and social information processing: Multiple risk-factor models for understanding aggressive behavior in antisocial youth, Law and Human Behavior, 33(6), 515-529. doi: https:// doi.org/10.1007/s10979-008-9171-7

Stillman, P.E., Van Bavel, J.J., \& Cunningham, W.A. (2015). Valence asymmetries in the human amygdala: Task relevance modulates amygdala responses to positive more than negative affective cues. Journal of Cognitive Neuroscience, 27(4), 842-851. doi:https://doi. org/10.1162/jocn_a_00756
Thompson, K.C., \& Morris, R.J. (2016). Theories of juvenile delinquency. In Juvenile delinquency and disability (pp. 41-53). Springer, Cham. https://doi.org/10.1007/978-3-319-29343-1_4

Thornberg, R., \& Wänström, L. (2018). Bullying and its association with altruism toward victims, blaming the victims, and classroom prevalence of bystander behaviors: a multilevel analysis. Social Psychology of Education, 21(5), 1133-1151. https://doi.org/10. 1007/s11218-018-9457-7

Vachon, D.D., \& Lynam, D.R. (2016). Fixing the problem with empathy: Development and validation of the affective and cognitive measure of empathy. Assessment, 23(2), 135-149. https://doi.org/10.1177/ 1073191114567941

Vachon, D.D., Lynam, D.R., \& Johnson, J.A. (2013). The (non)relation between empathy and aggression: Surprising results from a metaanalysis. Psychological Bulletin, 140(3), 751- 773. https://doi.org/ 10.1037/a0035236

Vaillancourt T., Hymel S., McDougall P. (2003). Bullying is power: Implications for school-based intervention strategies. Journal of Applied School Psychology, 19, 157-176. https://doi.org/10.1300/ J008v19n02_10

Vaillancourt, T., Hymel, S., \& McDougall, P. (2011). Why does being bullied hurt so much? Insights from neuroscience. In D. Espelage \& S. Swearer (Eds.), Bullying in North American Schools (pp. 23-33). New York, NY: Taylor \& Francis.

Vaillancourt, T., Hymel, S., \& McDougall, P. (2013). The biological underpinnings of peer victimization: Understanding why and how the effects of bullying can last a lifetime. Theory Into Practice, 52(4), 241-248. https://doi.org/10.1080/00405841.2013.829726

van Geel, M., Goemans, A., Toprak, F., \& Vedder, P. (2017). Which personality traits are related to traditional bullying and cyberbullying? A study with the Big Five, Dark Triad and sadism. Personality and Individual Differences, 106, 231-235. https://doi. org/10.1016/j.paid.2016.10.063

Viding, E., McCrory, E.J., Blakemore, S.J., \& Frederickson, N. (2011). Behavioural problems and bullying at school: Can cognitive neuroscience shed new light on an old problem? Trends in Cognitive Sciences, 15(7), 289-291. https://doi.org/10.1016/j.tics.2011.05.001

Vijayakumar, N., Cheng, T.W., \& Pfeifer, J.H. (2017). Neural correlates of social exclusion across ages: A coordinate-based meta-analysis of functional MRI studies. NeuroImage, 153, 359-368. https://doi.org/ 10.1016/j.neuroimage.2017.02.050

Volk, A.A., Camilleri, J.A., Dane, A.V., \& Marini, Z.A. (2012). Is adolescent bullying an evolutionary adaptation? Aggressive Behavior, 38(3), 222-238. https://doi.org/10.1002/ab.21418

Volk, A.A., Dane, A.V., \& Marini, Z.A. (2014). What is bullying? A theoretical redefinition. Developmental Review, 34(4), 327-343. https://doi.org/10.1016/j.dr.2014.09.001

Volk, A.A., Farrell, A.H., Franklin, P., Mularczyk, K.P., \& Provenzano, D.A. (2016). Adolescent bullying in schools: An evolutionary perspective. In D. C. Geary \& D. B. Berch (Eds.), Evolutionary perspectives on child development and education (pp. 167-191). Switzerland. Springer.

Ward, B.D. (2000). Simultaneous inference for fMRI data.

Weisz, E., \& Zaki, J. (2018). Motivated empathy: A social neuroscience perspective. Current Opinion in Psychology. https://doi.org/10. 1016/j.copsyc.2018.05.005

Wheeler, S., Book, A., \& Costello, K. (2009). Psychopathic traits and perceptions of victim vulnerability. Criminal Justice and Behavior, 36(6), 635-648. https://doi.org/10.1177/0093854809333958

Whiteside, S.P., \& Lynam, D.R. (2001). The five factor model and impulsivity: Using a structural model of personality to understand impulsivity. Personality and individual differences, 30(4), 669-689. https://doi.org/10.1016/S0191-8869(00)00064-7

Williams, K.D., \& Jarvis, B. (2006). Cyberball: A program for use in research on interpersonal ostracism and acceptance. Behavior 
Research Methods, 38(1), 174-180. https://doi.org/10.3758/ BF03192765

Wilson, K., Demetrioff, S., \& Porter, S. (2008). A pawn by any other name? Social information processing as a function of psychopathic traits. Journal of Research in Personality, 42(6), 1651-1656. https:// doi.org/10.1016/j.jrp.2008.07.006

Ybarra, M.L., Espelage, D.L., \& Mitchell, K.J. (2014). Differentiating youth who are bullied from other victims of peer-aggression: The importance of differential power and repetition. Journal of Adolescent Health, 55(2), 293-300. https://doi.org/10.1016/j. jadohealth.2014.02.009

Yeager, D.S., Dahl, R.E., \& Dweck, C.S. (2018). Why interventions to influence adolescent behavior often fail but could succeed. Perspectives on Psychological Science, 13(1), 101-122.https://doi. org/10.1177/1745691617722620
Yeager, D.S., Fong, C.J., Lee, H.Y., \& Espelage, D.L. (2015). Declines in efficacy of anti-bullying programs among older adolescents: Theory and a three-level meta-analysis. Journal of Applied Developmental Psychology, 37, 36-51. https://doi.org/10.1016/j.appdev.2014.11. 005

Zaki, J. (2014). Empathy: A motivated account. Psychological Bulletin, 140(6), 1608-1647. https://doi.org/10.1037/a0037679

Zink, C.F., Pagnoni, G., Martin, M.E., Dhamala, M., \& Berns, G.S. (2003). Human striatal response to salient nonrewarding stimuli. The Journal of Neuroscience, 23(22), 8092-8097. https://doi.org/ 10.1523/JNEUROSCI.23-22-08092.2003

Publisher's note Springer Nature remains neutral with regard to jurisdictional claims in published maps and institutional affiliations. 